\title{
Labyrinthotomy or Vestibulotomy in Anatomic and Congenital Variations of the Oval Window and Facial Nerve
}

\author{
Khalid A. Al-Mazrou ${ }^{\text {a }} \quad$ Yildirim A. Bayazit ${ }^{\mathrm{b}}$ \\ a Department of Otolaryngology, King Saud University and King Saud Bin Abdulaziz University for Health Sciences, \\ Riyadh, Saudi Arabia; ${ }^{b}$ Department of Otolaryngology, Faculty of Medicine, Gazi University, Ankara, Turkey
}

\section{Key Words}

Conductive hearing loss · Facial nerve - Vestibulotomy . Labyrinthotomy

\begin{abstract}
Objective: To present the results of our experience with labyrinthotomy or vestibulotomy in cases where the oval window is blocked by the facial nerve and in the presence of bilateral congenital agenesis of the oval window, respectively. Study design: Retrospective analysis of the records of the patients operated in two different centers. Methods: Between 2007 and 2012, 5 ears of 4 patients who were operated on in two different clinics with a presumptive diagnosis of otosclerosis were included in the study. There were 3 female patients and 1 male. The ages ranged from 10 to 26 (mean 19 years). All patients had unilateral conductive hearing loss except 1 (10-year-old girl or patient 1). Pure tone averages were calculated at the frequencies $0.5,1,2$ and $4 \mathrm{kHz}$ both pre- and postoperatively according to the Committee on Hearing and Equilibrium 1995 Guidelines for the Evaluation of Results of Treatment of Conductive Hearing Loss. All patients underwent a middle ear exploration and postoperatively the initial audiological examination was performed after 6 months. Results: Retrospective analysis revealed that vestibulotomy
\end{abstract}

or labyrinthotomy was performed in 5 ears of 4 patients. Postoperative dizziness was encountered in 2 patients who had vestibulotomy due to oval window agenesis, which ceased spontaneously at 1 month postoperatively. The perioperative period was otherwise uneventful. None of the patients had sensorineural hearing loss or deterioration of hearing. There was a significant improvement in hearing after the operation. A 28-dB improvement in the mean air conduction pure tone thresholds was achieved. Conclusion: Vestibulotomy and labyrinthotomy are safe and effective procedures in terms of hearing restoration, which can be applied in cases of congenital agenesis of the oval window or obstruction of the oval window by the facial nerve.

Copyright $\odot 2012$ S. Karger AG, Basel

\section{Introduction}

Although congenital agenesis of the oval window is a rare anomaly [1], its coexistence with or without facial nerve abnormalities is likely in children with maximal conductive hearing loss who have an otherwise healthy ear. The use of high resolution computed tomography allows us to diagnose minor ear malformations, reveal anomalies of the facial nerve and exclude juvenile

\section{KARGER}

Fax +41613061234

E-Mail karger@karger.com

www.karger.com
(C) 2012 S. Karger AG, Basel

0301-1569/12/0746-0320\$38.00/0

Accessible online at:

www.karger.com/orl
Yildırım A. Bayazıt, MD

Department of Otolaryngology

King Saud Bin Abdulaziz University for Health Sciences

King Abdulaziz Medical City, National Guard Hospital

Riyadh (Saudi Arabia), E-Mail bayazity@yahoo.com 
otosclerosis or inner ear malformations. The footplate normally measures $0.25 \mathrm{~mm}$ in thickness, and may be seen as a thin white line traversing the oval window, and occasionally it is not seen on the computed tomography scan.

Formation of the oval window is intimately related to the development of the stapes footplate, the annular ligament, the horizontal segment of the facial nerve canal, and the vestibular component of the otic capsule. In the 5 th week of gestation, the mass of stapes becomes recognizable as a ring-shaped structure around the stapedial artery. This rudimentary stapes grows medially, then contacts and indents the developing otic capsule at the future oval window during the 7 th week of gestation. The tissue in this depression fuses with the stapedial ring to form the stapes footplate. The stapes crura are recognizable by 14 weeks, ossification begins by 18 weeks, and the stapes appears in its infant form by 32 weeks. Once the base of the stapes has fully developed, dedifferentiation of the oval window cartilage occurs and a rim of fibrous tissue forms, producing the annular ligament. The stapes is thus adult in configuration at 35 weeks. When the primitive stapes fails to fuse with the primitive vestibule, the oval window cannot develop, resulting in its congenital absence. Malformation of the stapes is an expected concomitant finding given the close relationship of the stapes to the oval window during this developmental sequence. Failure of the annular ligament to completely form produces congenital fixation of the stapes footplate $[2,3]$.

The facial nerve also develops from the second branchial arch. The horizontal segment of the facial nerve is recognized by the 6th week of gestation when it passes between the developing membranous labyrinth and the primitive stapes. By week 8 , soon after the stapes blastema reaches the otic capsule, a sulcus forms within the lateral margin of the cartilaginous otic capsule, initiating the formation of the horizontal facial nerve canal. This groove forms by week 10. If this canal is deep and well formed, the facial nerve will be in its normal anatomic position against the otic capsule. The facial nerve groove will begin to enclose the facial nerve in the 4th gestational month. Ossification of the canal is completed during or shortly after the 1st year of life [3].

Exploratory tympanotomy has been performed to treat conductive hearing loss both in children and adults. Although congenital or acquired problems can cause conductive hearing loss, the most common pathology is otosclerosis, while congenital absence of the oval window is rare. Since McAksile and Sullivan [4] first reported pa- tients with congenital absence of stapes with bilateral conductive hearing deafness in 1955, more than 100 cases of congenital absence of the oval window have been reported $[5,6]$. The rate of finding any abnormality in otosclerosis surgery is around $25 \%$. These abnormalities may be bilateral in $7 \%$. Otosclerosis requiring an oval window drillout can be seen as much as $41 \%$, which is followed by dehiscent or overhanging facial nerves in $25 \%$ [7].

In this study, the purpose was to present the results of our experience with labyrinthotomy or vestibulotomy in cases where the oval window is blocked by the facial nerve and in the presence of bilateral congenital agenesis of the oval window, respectively.

\section{Methods}

Between 2007 and 2012, 5 ears of 4 patients who were operated on in two different clinics with a clinical diagnosis of otosclerosis were included in the study. There were 3 female patients and 1 male. The ages ranged from 10 to 26 (mean 19 years). All patients had unilateral conductive hearing loss except 1 (10-year-old girl or patient 1 ).

The preoperative diagnostic work-up included history, otoscopy, pure tone audiometry, tympanogram and acoustic reflex testing. Pure tone averages were calculated at the frequencies 0.5 , 1,2 and $4 \mathrm{kHz}$ both pre- and postoperatively according to the Committee on Hearing and Equilibrium 1995 Guidelines for the Evaluation of Results of Treatment of Conductive Hearing Loss [8]. Postoperatively, the initial audiological examination was performed after 6 months.

All patients underwent a middle ear exploration via endaural approach either under local or general anesthesia. The opening of the otic capsule or labyrinthotomy was performed using a standard microdrill. The power was adjusted to 5,000 rounds $/ \mathrm{min}$. Diamond drills with a diameter of 1 and $0.6 \mathrm{~mm}$ were used sequentially. A hand-held perforator and needle were used to open the endosteum as the grey discoloration of the inner ear was seen. After the placement of piston prosthesis, the opening in the otic capsule was sealed with fat around the piston.

\section{Results}

In all patients, otoscopy was normal and acoustic reflex was absent. Pure tone audiometry revealed that bone conduction thresholds were within normal limits (better than $25 \mathrm{~dB}$ ) in the test frequencies in all patients. Acoustic reflex was absent in the operated ear.

Patient 1 (10-year-old girl) with bilateral conductive hearing loss was operated on in both ears at 9-month intervals. In both surgeries labyrinthotomy was performed in the area corresponding to the location of the oval win- 
Fig. 1. a Note the abnormally shaped incus, the rudimentary stapes superstructure $(\mathrm{rS})$, and bifid facial nerve $(\mathrm{F})$ in the left ear. b Rudimentary stapes superstructure is removed in the left ear; the oval window (O) is absent. c Vestibulotomy (v) is performed in the area corresponding to the oval window in the left ear. $\mathbf{d}$ A Teflon piston ( $\mathrm{p}$ ) is placed between the bifid facial nerve branches (f) in the left ear.
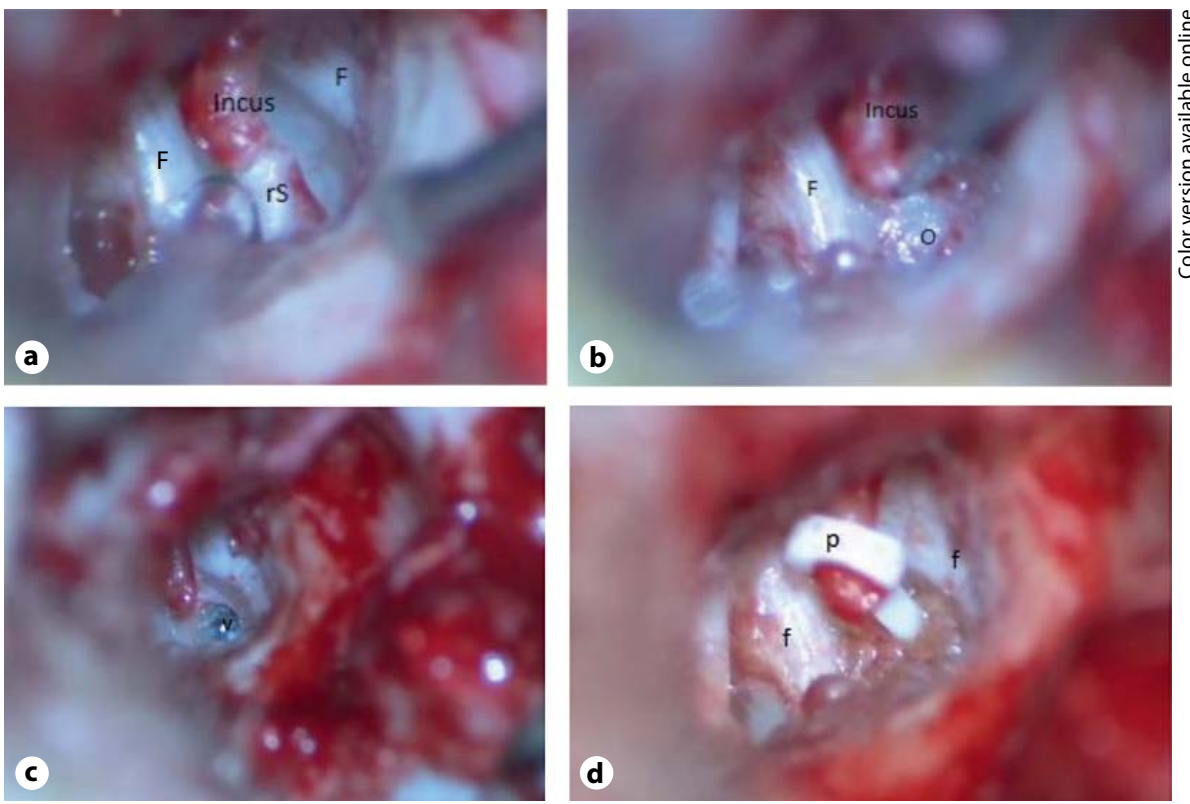

Table 1. Intraoperative findings of the patients

\begin{tabular}{|c|c|c|c|c|c|c|}
\hline \multicolumn{2}{|c|}{ Patient } & Ear & \multicolumn{3}{|l|}{ Middle ear status } & $\begin{array}{l}\text { Labyrinthotomy }{ }^{1} \\
\text { or vestibulotomy }^{2}\end{array}$ \\
\hline 1 & 10 & both & $\begin{array}{l}\text { malleus intact; incus abnormal } \\
\text { position and lenticular process lacks } \\
\text { stapes superstructure; rudimentary } \\
\text { stapedial tendon present }\end{array}$ & $\begin{array}{l}\text { splits into two around the } \\
\text { area corresponding to the } \\
\text { oval window on the left side; } \\
\text { normal course on the right side }\end{array}$ & agenesis & $\begin{array}{l}\text { between the facial } \\
\text { nerve branches }{ }^{2}\end{array}$ \\
\hline 2 & 17 & left & $\begin{array}{l}\text { malleus and incus intact } \\
\text { stapes fixed }\end{array}$ & overriding the oval window & $\begin{array}{l}\text { like a cleft } \\
\text { under the facial }\end{array}$ & $\begin{array}{l}\text { inferior to oval } \\
\text { window }^{1}\end{array}$ \\
\hline 3 & 26 & right & $\begin{array}{l}\text { malleus and incus intact } \\
\text { stapes fixed }\end{array}$ & overriding the oval window & $\begin{array}{l}\text { like a cleft } \\
\text { under the facial }\end{array}$ & $\begin{array}{l}\text { inferior to oval } \\
\text { window }^{1}\end{array}$ \\
\hline 4 & 24 & left & $\begin{array}{l}\text { malleus and incus intact } \\
\text { stapes fixed }\end{array}$ & overriding the oval window & $\begin{array}{l}\text { like a cleft } \\
\text { under the facial }\end{array}$ & $\begin{array}{l}\text { inferior to oval } \\
\text { window }^{1}\end{array}$ \\
\hline
\end{tabular}

dow, and a Teflon piston $(0.6 \times 4.5 \mathrm{~mm})$ was placed. Postoperative dizziness lasted for 1 month after each surgery and ceased spontaneously (fig. 1a-d).

Patient 2 (17-year-old girl) was operated on recently. Therefore, her audiological results were not included in the calculations. However, during her surgery, the facial canal was found to be traversing over a cleft-like oval window niche. A similar finding was also encountered in the operation of the remaining 2 adult patients where the facial nerve was coursing over the oval window. This con- dition did not allow stapedotomy or stapedectomy. Therefore, a fenestration was performed in the otic capsule inferior to the oval window. A Teflon piston was placed in 2 adults $(0.6 \times 4.5 \mathrm{~mm})$, and a smart piston $(0.5 \times 4.5 \mathrm{~mm})$ was placed in the 17-year-old girl (table 1).

The perioperative period was uneventful. None of the patients had sensorineural hearing loss or deterioration of hearing in the 6-month follow-up period. There was a significant improvement in hearing after the operation (table 2). 
Table 2. Hearing results of the patients

\begin{tabular}{|c|c|c|c|c|c|}
\hline \multicolumn{2}{|c|}{ Patient } & \multicolumn{2}{|c|}{ Bone conduction PTA, dB } & \multicolumn{2}{|c|}{ Air conduction PTA, dB } \\
\hline No. & age & preoperative & $\begin{array}{l}\text { postoperative } \\
6 \text { months }\end{array}$ & preoperative & $\begin{array}{l}\text { postoperative } \\
6 \text { months }\end{array}$ \\
\hline 1 & 10 years, first ear & 18 & 23 & 65 & 26 \\
\hline 1 & 10 years, second ear & 20 & 26 & 58 & 32 \\
\hline 2 & 17 years & 22 & - & 62 & - \\
\hline 3 & 26 years & 24 & 26 & 52 & 30 \\
\hline 4 & 24 years & 25 & 28 & 49 & 24 \\
\hline \multicolumn{2}{|c|}{ Mean } & 21.8 & 25.8 & 56 & 28 \\
\hline
\end{tabular}

PTA $=$ Pure tone average

\section{Discussion}

Exploratory tympanotomy for conductive hearing loss has been performed mostly with a presumptive diagnosis of otosclerosis, especially in adults. There are mainly two critical anatomical problems which can be encountered during these surgeries, i.e. closure of the oval window by an abnormally positioned facial nerve and oval window agenesis. Both are congenital problems attributable to the second branchial arch, which is important in the development of facial nerve and stapes. The facial nerve and the superstructure and lateral part of the stapes footplate develop from the second branchial arch, and the vestibular part of the footplate originates from the otic vesicle. The stapes primordium at the tip of the Reichert cartilage pushes the facial nerve posteriorly, resulting in the formation of the vertical and horizontal segment of the facial nerve. The course of facial nerve may be abnormal in cases of lack of oval window formation [9].

Congenital agenesis of the oval window involves complete osseous obliteration of the oval window either by a concentric narrowing that produces a dimple-like depression along the medial tympanic wall or by a thick bony plate. The stapes superstructure may be present or absent, but there is no footplate or annular ligament, in contrast to congenital otosclerosis [2, 10]. Bilateral absence of the oval window has been reported in several cases $[5,11,12]$. In bilateral cases, the middle ear anomalies may be similar or different. In our study, bilateral congenital agenesis of the oval window was encountered in 1 of the cases (patient 1), and the middle ear anomalies were different in both sides regarding the facial nerve.

Almost $76 \%$ of the patients with congenital absence of the oval window have malformation of the facial nerve canal [3]. An overhanging facial nerve is present in $32 \%$ of stapedectomy cases [13]. However, in the absence of oval window agenesis, an abnormal course of the facial nerve is also likely. This condition may also be associated with conductive hearing loss [13]. The nerve can either limit complete exposure of the oval window or it can cover the footplate completely. In the former condition, a partial promontory approach can be applied. In a series of patients, successful hearing restoration with stapedectomy and piston prosthesis placement was reported, which was comparable to nonpromontory cases [14]. It is not possible to perform a partial promontory approach in cases where the facial nerve completely obstructs the oval window. This was the condition in our remaining patients. Therefore, we had to perform labyrinthotomy in the area below the oval window.

In the absence of the oval window or obstruction of the oval window by the facial nerve, there are several ways for hearing amplification: vestibulotomy (fenestration of the oval window), fenestration of the lateral semicircular canal, conventional hearing aids, active middle ear implants to stimulate the inner ear through the round window and bone-anchored hearing aids.

Surgical methods have been described in an attempt to transmit the sound energy into the inner ear through piston prosthesis. Lambert [15] described fenestration of the oval window. Although lateral canal fenestration is an old technique, the modified Lempert fenestration of the horizontal semicircular canal has been proposed a good choice as reported in 2 patients [11]. It was suggested that vestibulotomy above a severely displaced facial nerve represents a new surgical approach to achieve serviceable hearing, and that the lack of facial nerve injury and the potential for hearing restoration make this pro- 
cedure feasible in patients who would otherwise be marginal or poor surgical candidates [16]. In our experience, the labyrinthotomy was performed below the oval window as in promontory cochleostomy using a standard microdrill and diamond burrs. Initially, a 1-mm-diameter burr is preferred to prevent sudden penetration into the labyrinth. Meticulous control is needed during the procedure. As the greyish reflection of the labyrinth is seen, a $0.6-\mathrm{mm}$ drill can be used until the exposure of the endosteum. At this stage a footplate perforator can be used to enlarge the opening by removing the bone dust. After the placement of the piston prosthesis, the labyrinthotomy site is sealed by pieces of fat around the prosthesis.

It was suggested that the long-term hearing results from this procedure may not warrant the risks involved for the minimal gains in hearing [15]. Up to $31 \%$ of patients may require a revision surgery for hearing deterio- ration [10]. On the other hand it was also reported that inner ear fenestration surgery results in improvement in hearing with stable results [12]. In addition, vestibulotomy in cases of oval window absence is a relatively safe and effective procedure, which can be performed even in the presence of abnormal facial nerve passing under the oval window or its area in cases of oval window dysplasia [17]. Despite the difference in results, stapedectomy for congenital fixation remains an effective method to achieve significant hearing improvement in the majority of patients [18]. In our experience, the hearing of the patients improved after the surgery. None of the patients had sensorineural hearing loss or deterioration of hearing.

In conclusion, both vestibulotomy and labyrinthotomy are safe and effective procedures in terms of hearing restoration, which can be applied in cases of congenital agenesis of the oval window or obstruction of the oval window by the facial nerve.

\section{References}

1 Pou JW: Congenital absence of the oval window. Report of two cases. Laryngoscope 1963;73:384-391.

$>2$ Zeifer B, Sabini P, Sonne J: Congenital absence of the oval window: radiologic diagnosis and associated anomalies. AJNR Am J Neuroradiol 2000;21:322-327.

$\checkmark 3$ Jahrsdoerfer RA: Congenital absence of the oval window. ORL J Otorhinolaryngol Relat Spec 1977;84:904-914

$\checkmark 4$ McAksile K, Sullivan JA: Surgical management of congenital atresia of the ear. J Laryngol Otol 1955;69:765-785.

5 Sterkers JM, Sterkers O: Surgical management of congenital absence of the oval window with malposition of the facial nerve. Adv Otorhinolaryngol 1988;40:33-37.

$\checkmark 6$ Hough JV: Malformations and anatomical variations seen in the middle ear during the operation for mobilization of stapes. Laryngoscope 1958;68:1337-1379.
7 Daniels RL, Krieger LW, Lippy WH: The other ear: findings and results in 1,800 bilateral stapedectomies. Otol Neurotol 2001;22: 603-607.

$>8$ Committee on Hearing and Equilibrium: Committee on Hearing and Equilibrium guidelines for the evaluation of results of treatment of conductive hearing loss. Otolaryngol Head Neck Surg 1995;113:186-187.

$\checkmark 9$ Harada T, Black FO, Sando I, Singleton GT: Temporal bone histopathologic findings in congenital anomalies of the oval window. Otolaryngol Head Neck Surg 1980;88:275-287.

10 Alarcon A, Jahrsdoerfer RA, Kesser BW: Congenital absence of the oval window: diagnosis, surgery, and audiometric outcomes. Otol Neurotol 2007;29:23-28.

11 Yi Z, Yang J, Li Z, Zhpu A, Lin Y: Bilateral congenital absence of stapes and oval window in 2 members of a family: etiology and management. Otolaryngol Head Neck Surg 2003;128:777-782.

-12 Hasegawa J, Kawase T, Hidaka H, Oshima T, Kobayashi T: Surgical treatment for congenital absence of the oval window with facial nerve anomalies. Auris Nasus Larynx 2012; 39:249-255.
3 Al-Mazrou KA, Alorainy IA, Al-Dousary SH, Richardson MA: Facial nerve anomalies in association with congenital hearing loss. Int J Pediatr Otorhinolaryngol 2003;67: 1347-1353.

14 Inserra MM, Mason TP, Yoon PJ, Roberson JB Jr: Partial promontory technique in stapedotomy cases with narrow niche. Otol Neurotol 2004;25:443-446.

15 Lambert PR: Congenital absence of the oval window. Laryngoscope 1990;100:37-40.

16 Han D, Zhao S, Wang D, Guo J, Dai H: Vestibulotomy above a severely displaced facial nerve. Acta Otolaryngol 2005;125:962-965.

17 Martin C, Oletski A, Bertholon P, Prades JM: Abnormal facial nerve course associated with stapes fixation or oval window absence: report of two cases. Eur Arch Otorhinolaryngol 2006;263:79-85.

18 Massey BL, Hillman TA, Shelton C: Stapedectomy in congenital stapes fixation: are hearing outcomes poorer? Otolaryngol Head Neck Surg 2006;134:816-818. 